\title{
Influence of Segmental Joints in the Segmental Circular Tunnel Lining under the Impact of Earthquakes
}

\author{
Gospodarikov Alexandr $*^{1}$ and Thanh Nguyen Chi*2 \\ * Saint Petersburg Mining University, Saint Petersburg, Russia Federation \\ gospodarikov@mail.ru \\ 2nguyenthanh.xdetn47@gmail.com
}

\begin{abstract}
At present, the underground construction system is developing very strongly in the world and in Vietnam. In particular, the metro tunnel system was developed very rapidly due to its ability to serve in the urban transport system. Most tunnels in the metro system today use the segmental tunnel lining, which has segmental joints in the segmental tunnel lining due to its advantages. Tunnels these have circular cross section are very popular in metro tunnels system. In this paper, the methods of calculating the impact of earthquake on tunnels lining in the case of the tunnel has lining continuous or segmental (with segmental joints between segments of lining tunnel) have been used to comparisons of internal forces, displacement of tunnel lining in two cases under the impact of earthquake and comments about effects of segmental joints in the segmental tunnel lining. This paper is used as a case study for the Hanoi metro tunnel.
\end{abstract}

Keyword - Tunnel, segmental lining, earthquake, joints, effect, earthquake.

\section{INTRODUCTION}

At present, tunnels for transportation and infrastructure are developing rapidly in the world and Viet Nam. Due to these tunnels's characteristics, tunnels may be heavily influenced by earthquakes that could impact to the area, where tunnels are located. There are many methods of calculating the impact of earthquakes to tunnels, such as methods of Wang, Pezien and Wu.... However, these methods have disadvantages such as: considering the environment the rock surrounding the tunnel and the tunnel lining are models that operate in linear elastic state, the tunnel lining is continuous.

In actually design, construction of tunnels, the segmental tunnel lining could be used to tunnels, especially with tunnels under the impact of earthquakes. In the literature, effects of segmental joints on the tunnel lining are usually considered in both indirect methods and direct methods. With indirect methods are concerned, the tunnel lining is perceived as a rigid lining ring embedded on a continuous ground model, to consider the segmental lining as a continuous ring with a reduced rigidity by applying a reduction factor, $\eta$, to the bending rigidity $(E I)$ of the tunnel lining [1]: where $(E I)_{e q}$ is the bending stiffness of the tunnel segmental lining, $(E I)$ is the bending stiffness of the continuous lining (Muir Wood, Einstein và Schwartz, Takano, Oreste) [2]-[5]. The effect of joints in the tunnel lining taken into calculation through a reduced rigidity of the tunnel lining. The ground-structure interaction is usually considered by means of so-called bedded ring models, in which the ground reaction is taken into consideration by means of discrete springs according to Winkler's theory. In direct methods, segmental joints has been added directly to the tunnel lining (Lee et al, Blom, Ding et al, Naggar) [6] [9]. In Ding et al method, has got effects of three joint stiffnesses to the tunnel lining, these be the rotational stiffness, the axial stiffness and the radial stiffness. But in this method not could calculation to case of cases in which the joint distribution is asymmetrical to the vertical axis of the tunnel.

In this study, Wang and Pezien's methods [10]-[12] were used calculate for the tunnel lining continuous under the impact of the earthquake and this paper constructed a tunnel's model by the Abaqus software program to calculate the impact of earthquake on the tunnel lining for the case of the tunnel lining continuous. Finally, the HRM method has been used calculate to the tunnel lining for two cases, the tunnel lining continuous and the segmental tunnel lining under the impact of the earthquake. Base the results obtained, given comments on the effect of joints to the tunnel lining under the impact of the earthquake. The data of a cross-section of subway tunnel Hanoi has been used as a case studied and results of calculation methods are discussed.

\section{THE CASE STUDIED: CHARACTERISTICS OF HANOI METRO TUNNEL}

In this study, for the purpose of comparing results of different calculation methods, a typical cross section of the Hanoi tunnel metro system is chosen [14]. The tunnel is located at a depth of $20 \mathrm{~m}$ from the surface ground. The tunnel has got cross section is circular with the tunnel radius $\mathrm{R}=3.15 \mathrm{~m}$. The tunnel lining has been made reinforced concrete. The tunnel lining design parameters as listed below: Young's modulus $E_{l}=35500 \mathrm{MPa}$; Poisson's ratio $v_{l}=0.15$; lining thickness $t_{l}=0.3 \mathrm{~m}$. 
Some characteristics of the strongest earthquakes that can occur in the Hanoi area are [15]:

- Earthquake has got magnitude maximum $\mathrm{M}_{\mathrm{W}}$ of 6.5;

- Distance from the epicentre of the earthquake, that has got magnitude maximum to Hanoi centre is 20 to 50 $\mathrm{km}$ and peak ground acceleration $\mathrm{a}_{\max }=0.2 \mathrm{~g}$.

Parameters of layers soils in Hanoi centre, where has got the metro tunnel, these have been determined through extensive in situ and laboratory tests (in Table I).

TABLE I. Parameters of Layers Soil in Hanoi Centre these be Determined through Extensive in Situ and Laboratory Tests [7]

\begin{tabular}{|c|c|c|c|c|}
\hline $\begin{array}{c}\text { Number of } \\
\text { soil layers }\end{array}$ & $\begin{array}{c}\text { Elastic } \\
\text { module, } \boldsymbol{E}, \mathbf{M P a}\end{array}$ & $\begin{array}{c}\text { Poisson's } \\
\text { ratio, } \boldsymbol{\mu}\end{array}$ & $\begin{array}{c}\text { Thickness of } \\
\text { layer } \mathbf{( h ) , ~} \mathbf{~ m}\end{array}$ & $\begin{array}{c}\text { Density of the } \\
\text { soil, } \boldsymbol{\rho}, \mathbf{g} / \mathbf{c m} 3\end{array}$ \\
\hline 1 & 9.25 & 0.41 & 4.6 & 1.75 \\
\hline 2 & 7.68 & 0.38 & 1.1 & 1.76 \\
\hline 3 & 15.3 & 0.35 & 11.8 & 1.81 \\
\hline 4 & 35.02 & 0.33 & 12.5 & 1.78 \\
\hline 5 & 53.9 & 0.32 & 11.0 & 1.83 \\
\hline 6 & 65 & 0.3 & 7.0 & 1.86 \\
\hline
\end{tabular}

\section{CALCULATION METHODS}

\section{A. Wang's Method [10]}

In 1993, Wang given this method that could calculation for the tunnel lining continuous under the impact of the earthquake. In this method, has got two case of, in the first case: full - slip at the soil - lining tunnel's, the internal forces on the tunnel lining can be written:

Where

$$
\begin{aligned}
T & = \pm \frac{1}{6} K_{1} \frac{E}{\left(1+v_{l}\right)} R \gamma_{\text {max }} \cos \left[2\left(\theta+\frac{\pi}{4}\right]\right. \\
M & = \pm \frac{1}{6} K_{1} \frac{E}{\left(1+v_{l}\right)} R \gamma_{\text {max }}^{2} \cos \left[2\left(\theta+\frac{\pi}{4}\right]\right. \\
K_{1} & =\frac{12\left(1-v_{l}\right)}{2 F+5-6 v_{l}}
\end{aligned}
$$

In case no-slip at the soil - lining tunnel's, only the normal forces $(T)$ can be expressed by Wang [1993]:

$$
\begin{aligned}
& T= \pm \frac{1}{2} K_{2} \frac{E}{\left(1+v_{l}\right)} R \gamma_{\max } \cos \left[2\left(\theta+\frac{\pi}{4}\right]\right. \\
& K_{2}=1+\frac{F\left[\left(1-2 v_{l}\right)-\left(1-2 v_{l}\right) C\right]-\frac{1}{2}\left(1-2 v_{l}\right)^{2}+2}{F\left[\left(3-2 v_{l}\right)+\left(1-2 v_{l}\right) C\right]+C\left[\frac{5}{2}-8 v_{l}+6 v_{l}^{2}\right]+6-8 v_{l}} \\
& C=\frac{E\left(1-v_{s}^{2}\right) R}{E_{S} t\left(1+v_{l}\right)\left(1-2 v_{l}\right)} \\
& F=\frac{E\left(1-v_{s}^{2}\right) R^{3}}{6 E_{S} J_{S}\left(1+v_{l}\right)} \\
& G=\frac{E}{2\left(1+v_{l}\right)}
\end{aligned}
$$

In 2013, Kouretzis el al proposed an equation of the maximum bending moment in lining tunnel under no slip condition when effect dynamic loading, this to improve the Wang's method.

$$
M_{K}= \pm\left(2-K_{3}-2 K_{4}\right) \tau_{\max } \frac{R^{2}}{2}
$$




$$
\tau_{\max }= \pm V_{\max } \sqrt{\rho_{\max } G_{\max }}
$$

Where $\tau_{\max }$ - the maximum free field seismic shear stress, $\rho_{\max }$ - density of the surround ground, $G_{\max }-$ the maximum ground shear modulus, $V_{\max }$ - the peak seismic velocity due to shear wave propagation.

$$
\begin{aligned}
& K_{3}=1+\frac{(1-2 v)(1-\mathrm{C}) \mathrm{F}-0.5(1-2 v) \mathrm{C}+2}{[(3-2 v)+(1-2 v) \mathrm{C}] F+[0.5(5-6 v)](1-2 v) \mathrm{C}+(6-8 v)} \\
& K_{4}=\frac{[1+(1-2 v) \mathrm{C}] \mathrm{F}-[0.5(1-2 v) \mathrm{C}]-2}{[(3-2 v)+(1-2 v) \mathrm{C}] F+[0.5(5-6 v)](1-2 v) \mathrm{C}+(6-8 v)}
\end{aligned}
$$

Where $K_{I}$ is full-slip lining response coefficient; $K_{2}$ is no-slip lining response coefficient; $F$ is flexibility ratio of tunnel lining; $C$ is compressibility ratio of tunnel lining; $E_{s}$ is Young's modulus of tunnel lining; $v_{s}$ is Poisson's ratio of tunnel lining; $R$ is tunnel radius; $t$ is thickness of tunnel lining; $J_{s}$ is inertia moment of tunnel lining per unit length of the tunnel (per unit width); $v_{l}$ is Poisson's ratio of ground mass surrounding the tunnel lining; $E$ is Young's modulus of ground mass surrounding the tunnel lining; $G$ is shear modulus of ground mass surrounding the tunnel lining; ; $I$ is moment of inertia of the tunnel lining; $\gamma_{\max }$ is maximum free-field shear strain; $\theta$ is angle measured counter-clockwise from spring line on the right; $T$ is normal forces and $M$ is bending moment in the tunnel lining.

\section{B. Penzien's Method [11]-[12]}

Penzien\&Wu (1998) and Penzien (2000) given similar analytical solutions for the internal forces on the tunnel lining. In case full-slip condition at the soil-lining:

$$
\begin{aligned}
& T=-\frac{12 E_{s} I \Delta d_{\text {lining }}^{n}}{d^{3}\left(1-v_{s}^{2}\right)} \cos 2\left(\theta+\frac{\pi}{4}\right) \\
& M=-\frac{6 E_{s} I \Delta d_{\text {lining }}^{n}}{d^{2}\left(1-v_{s}^{2}\right)} \cos 2\left(\theta+\frac{\pi}{4}\right) \\
& V=-\frac{24 E_{s} I \Delta d_{\text {lining }}^{n}}{d^{3}\left(1-v_{S}^{2}\right)} \sin 2\left(\theta+\frac{\pi}{4}\right) \\
& \pm \Delta d_{\text {lining }}^{n}= \pm R^{n} \Delta d_{\text {free-field }} \\
& R^{n}= \pm \frac{4(1-v)}{\alpha^{n}+1} \\
& \alpha^{n}=\frac{12 E_{s} I(5-6 v)}{d^{3} G\left(1-v_{s}^{2}\right)}
\end{aligned}
$$

With the case of no-slip condition:

$$
\begin{aligned}
& \pm \Delta d_{\text {lining }}= \pm R \Delta d_{\text {free-field }}=R \frac{\gamma_{\text {max }} d}{2} \\
& T=-\frac{24 E_{s} I \Delta d_{\text {lining }}}{d^{3}\left(1-v_{s}^{2}\right)} \cos 2\left(\theta+\frac{\pi}{4}\right) \\
& M=-\frac{6 E_{s} I \Delta d_{\text {lining }}}{d^{2}\left(1-v_{s}^{2}\right)} \cos 2\left(\theta+\frac{\pi}{4}\right) \\
& R= \pm \frac{4(1-v)}{\alpha+1} \\
& \alpha=\frac{24 E_{s} I(3-4 v)}{d^{3} G\left(1-v_{s}^{2}\right)}
\end{aligned}
$$




\section{HRM Method [1], [16]-[18]}

Method HRM is a direct method. This is part of the numerical method, method HRM used to Matlab program to construction model of tunnel lining and environment ground surrounding tunnel [16]-[17]. This method simulates the interaction between the lining and ground surrounding the tunnel through a number of independent "Winkler" type springs. The method HRM requires the definition of the active loads that apply directly to the support structure. These loads can be estimated using different methods of Mashimo and Ishimura [18].

Note: In case of the tunnel has got impact of the earthquake, method HRM needed to adjust: all the external loads are rotated counter-clockwise by $45^{0}$ and the horizontal loads are in opposite directions.

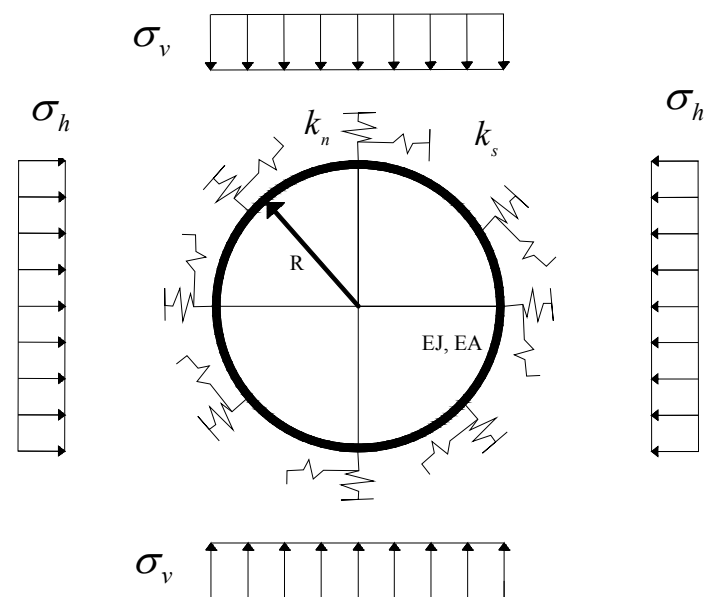

Fig. 1. Calculation scheme of tunnel lining with the HRM method. $\sigma_{\mathrm{v}}$ : vertical load in the model tunnel - surrounding ground; $\sigma_{\mathrm{h}}$ : horizontal load in the model tunnel - surrounding ground; $\mathrm{k}_{\mathrm{n}}$ : normal stiffness of the interaction springs; $\mathrm{k}_{\mathrm{s}}$ : tangential stiffness of the interaction springs; R: tunnel radius; EJ and EA: bending and normal stiffness of the tunnel lining [10].

\section{2D Numerical Method}

The soil environment around the tunnel and the tunnel lining behave linearly and elastically. In this method, has not got effect of gravity and drained conditions. A time history analysis has carried out using data of El Centro earthquake [19] (with characteristics of the El Centro earthquake almost identical to characteristics of the strongest earthquake that can occur in the Hanoi) $-\mathrm{M}_{\mathrm{w}}=6.5$ richter (in Fig. 2). 2D numerical method be calculation for case no-slip at the soil - lining tunnel's. In this model, soil layers are replaced with a single soil layer with equivalent properties: Young's modulus, $\mathrm{E}=35.75 \mathrm{Mpa}$; Poisson's ratio, $\mu=0.34$.

The 2D numerical model is $180 \mathrm{~m}$ wide in the $\mathrm{x}$-direction, $80 \mathrm{~m}$ in the z-direction. Phases of the construction process of tunnel in this study, have got 3 phases: Phase 1 (model setup): the setup of the model, assignment of the plane strain boundary conditions, there is no reflection wave at the boundary of model and has not got the influence of the gravity (Fig. 3); Phase 2: Construction of the tunnel lining with parameters of soil layer and lining tunnel, assigning the lining tunnel's with layer soil link conditions. Setting up the pressure over the whole tunnel boundary on both tunnel lining and model's boundary, assign the acceleration shifts of the earthquake to the model (see Fig. 4); Phase 3: Results obtained of the model (see Figures. 4, 9, 10, 11).

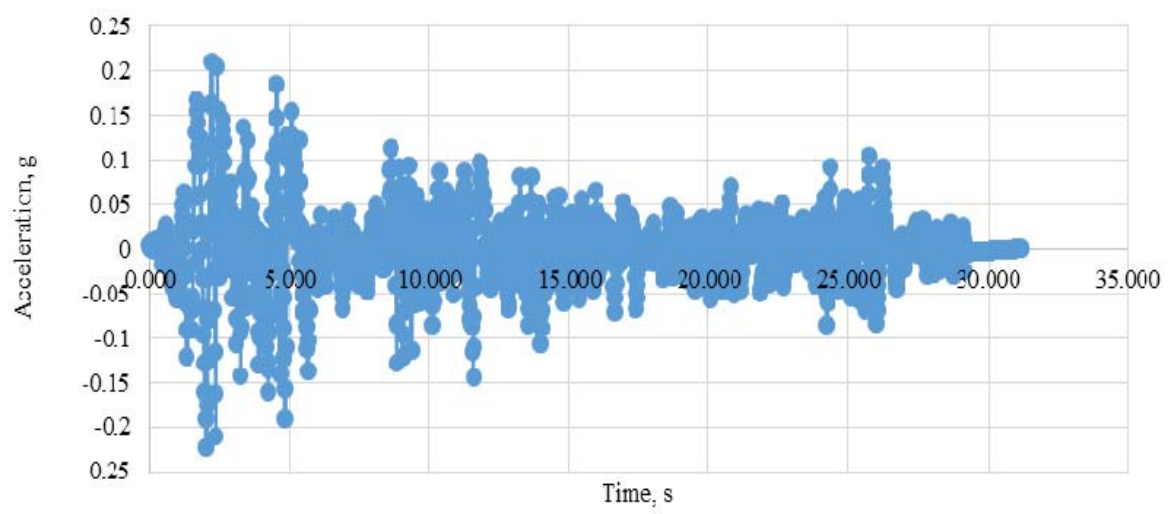

Fig. 2. Data of the El Centro earthquake 


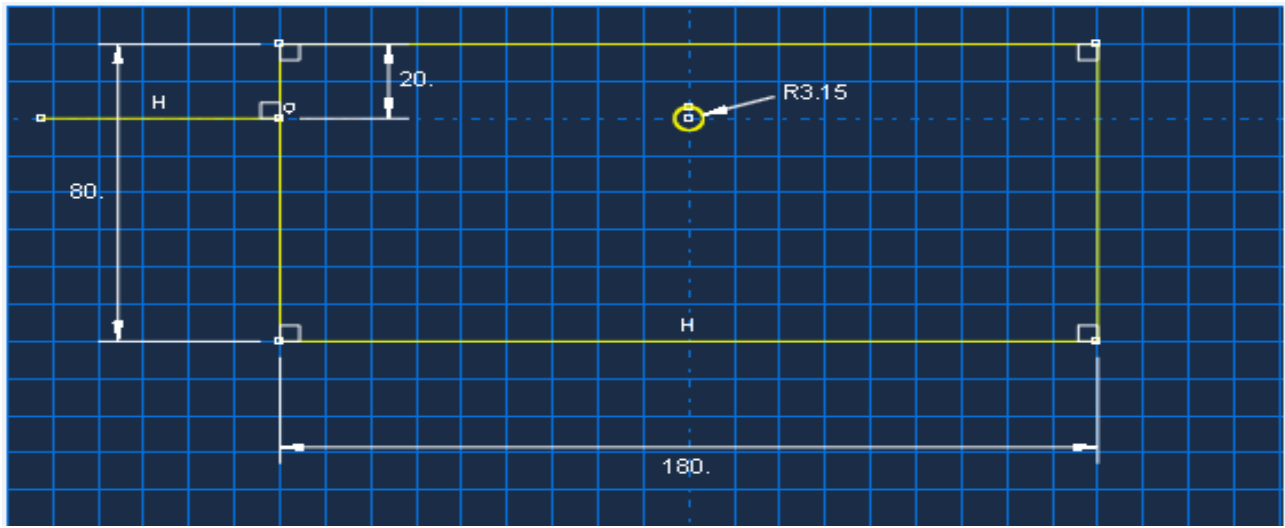

Fig.3. Geometry problem of the 2D numerical method

\section{IV.RESULTS AND DISCUSSION}

All results, these may be obtained from the use of the above methods, are given in Table II. The graphs for the internal forces appearing on the tunnel lining continuous according to the methods of Wang and Pezien \& $\mathrm{Wu}$ seen in the Fig. 7. The results of internal forces on the tunnel lining continuous obtained by 2D numerical method using Abaqus program were shown in Figures. 4, 5, 6. In the Fig. 8 demonstration of the internal force and movement on the tunnel lining under the impact of the earthquake was calculated by HRM method in two cases: the tunnel lining continuous and the segmental tunnel lining, with segmental joints in the tunnel lining.

Make comparisons of results obtained by different methods (in Table II). It was found that with the first three methods, Wang's analytical method, Pezien and Wu's analytical method, and 2D numerical method using Abaqus program, the results were quite close to each other and the deviation was not large. With the HRM method, in the case of the tunnel lining continuous, the internal forces obtained on the tunnel lining is not significantly different from the results of the above three methods, however. In the case of the segmental tunnel lining with the presence of segment joints in the tunnel lining, the internal forces on the tunnel lining significantly reduced, which is typical of the stresses on the tunnel lining. The displacement of this tunnel lining also increased compared to the case the tunnel lining is continuous.

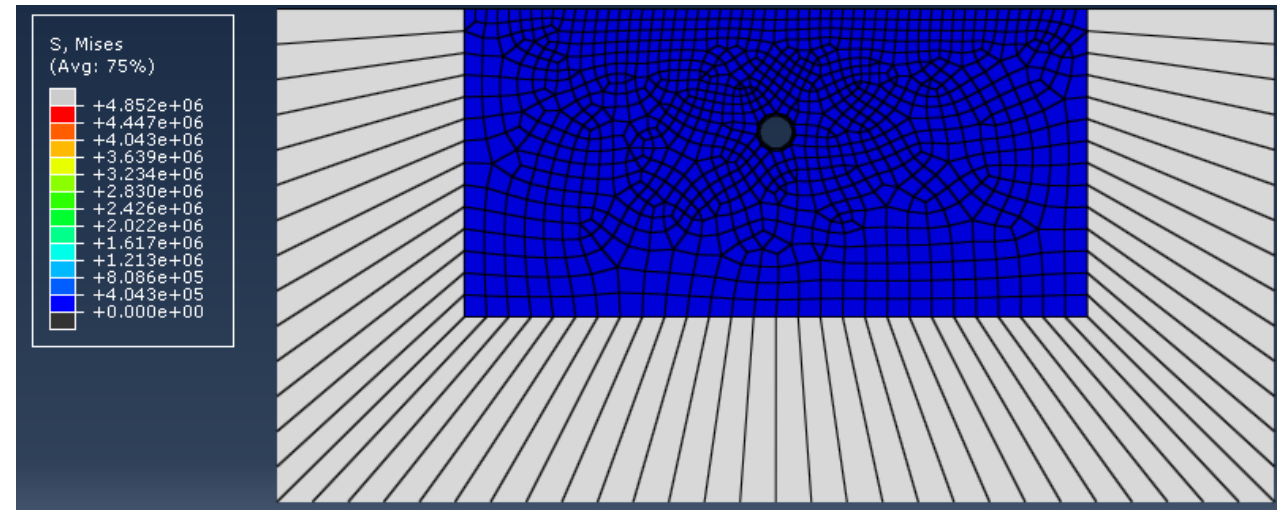

Fig.4. Results of the 2D numerical method

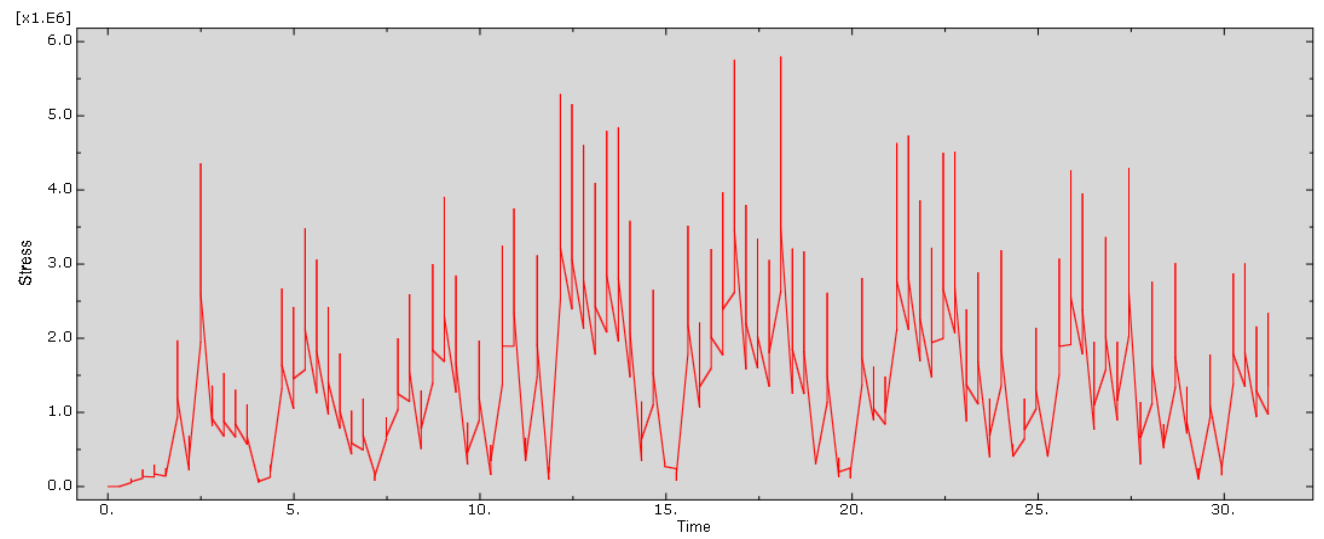

Fig.5. State stress on tunnel lining in 2D numerical method 


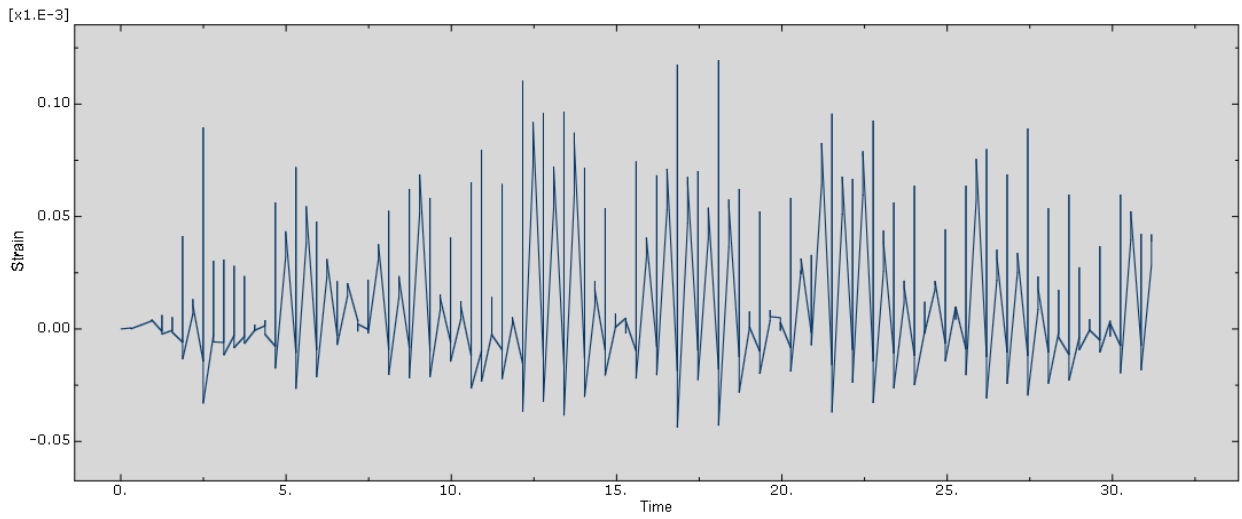

Fig.6. Strain of tunnel lining in 2D numerical method

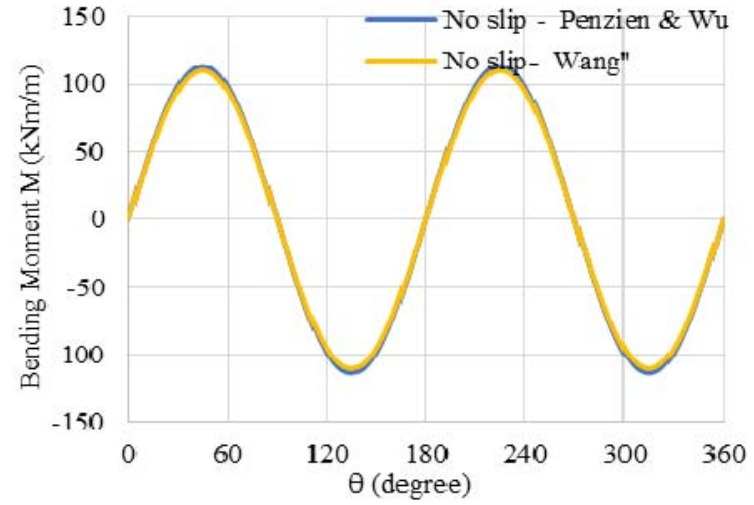

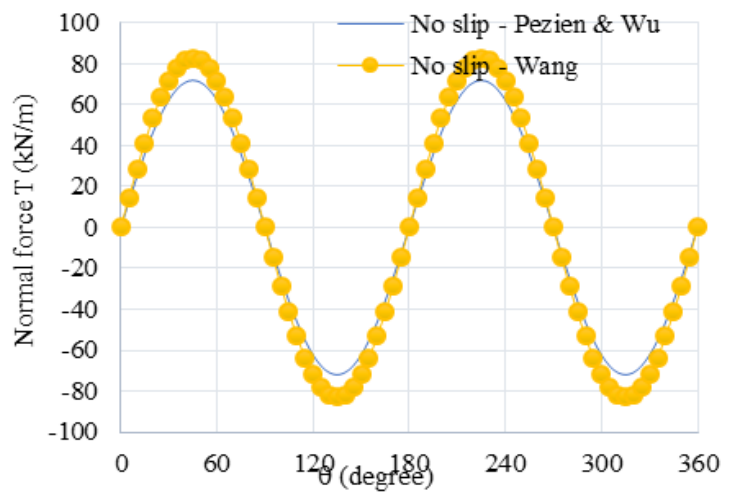

Fig.7. Bending Moment M (kNm/m), b - Normal force $\mathrm{T}(\mathrm{kN} / \mathrm{m})$ in Wang and Pezien \& Wu's method
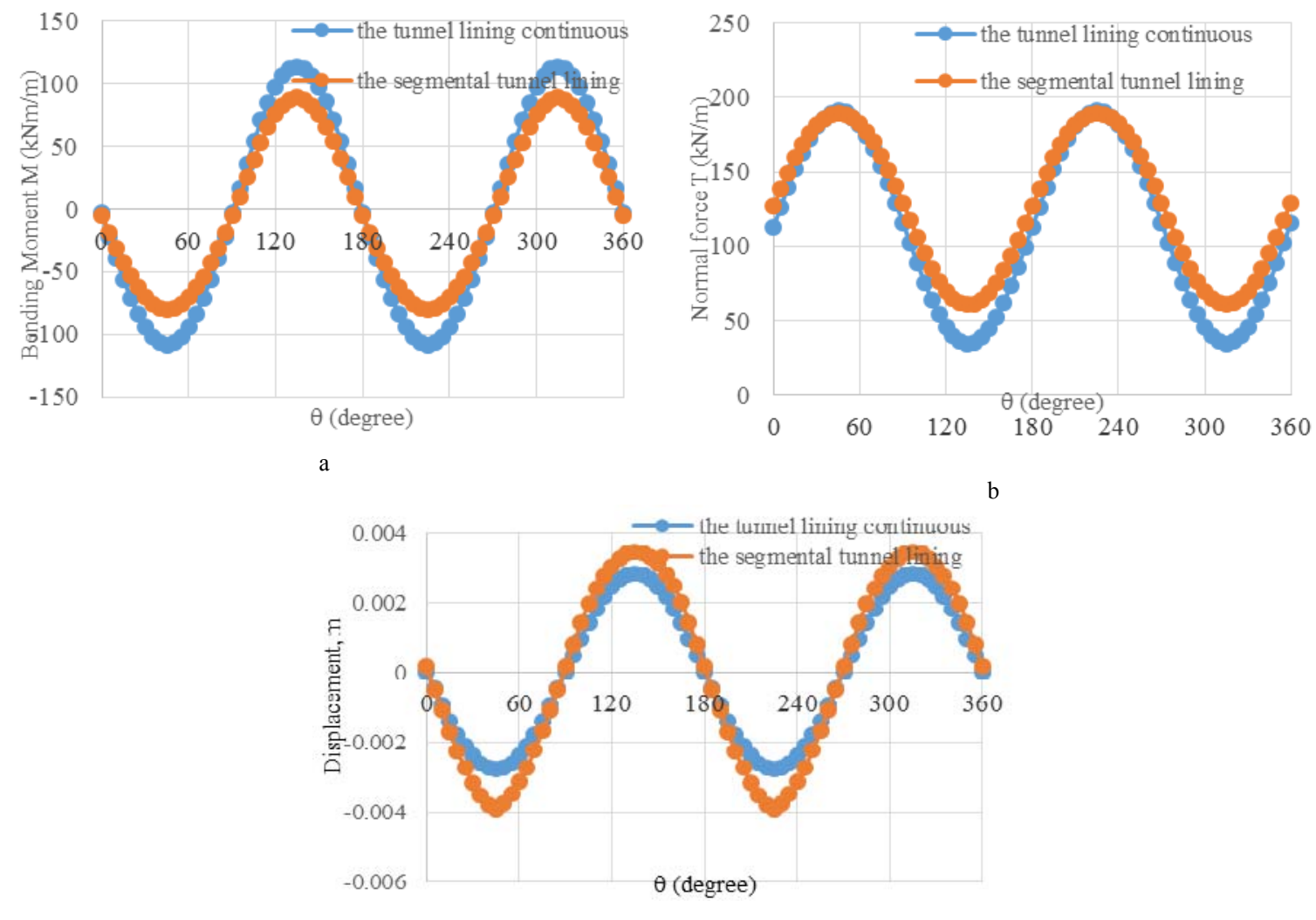

Fig.8. a - Bending Moment M ( $\mathrm{kNm} / \mathrm{m})$ in HRM method, b - Normal force T $(\mathrm{kN} / \mathrm{m})$, c - Displacement (m) in HRM method, 
TABLE II. Analysis Results of Different Calculation Methods

\begin{tabular}{|c|c|c|c|c|c|}
\hline $\begin{array}{c}\text { The internal forces } \\
\text { in lining tunnel }\end{array}$ & $\begin{array}{c}\text { Wang's method } \\
\text { (reference case) }\end{array}$ & $\begin{array}{c}\text { Penzien \& } \\
\text { Wung's method }\end{array}$ & $\begin{array}{c}\text { 2D numerical } \\
\text { method }\end{array}$ & $\begin{array}{c}\text { The tunnel lining } \\
\text { continuous }\end{array}$ & $\begin{array}{c}\text { The segmental } \\
\text { tunnel lining }\end{array}$ \\
\hline $\mathrm{M}(\mathrm{kN} \cdot \mathrm{m} / \mathrm{m})$ & 110.03 & 113.34 & - & 106.64 & 88.89 \\
\hline $\begin{array}{c}\text { \% difference with the } \\
\text { reference case of } \\
\text { bending moment on } \\
\text { the tunnel lining }\end{array}$ & - & 3.00 & - & 3.08 & 19.21 \\
\hline $\begin{array}{c}\mathrm{T}(\mathrm{kN} / \mathrm{m}) \\
\text { \% difference with the } \\
\text { reference case of } \\
\text { bending moment on } \\
\text { the tunnel lining }\end{array}$ & 82.95 & 71.96 & - & 190.34 & 189.12 \\
\hline $\begin{array}{c}\sigma(\mathrm{MPa}) \\
\text { \% difference with the } \\
\text { reference case of } \\
\text { stress on the tunnel } \\
\text { lining }\end{array}$ & 5.626 & 13.25 & - & 129.46 & 127.99 \\
\hline
\end{tabular}

Maximum displacement of the tunnel lining continuous under the impact of earthquakes, $\mathrm{d}_{\max }=2.8 \mathrm{~mm}$ and with the segmental tunnel lining and segmental joints, $d_{\max }=4 \mathrm{~mm}$.

The max bending moment values on the tunnel lining obtained by the Wang's method are not significantly different from max bending moment values of Pezien's method ( $3 \%$ is different). Compared with the torque value in the tunnel lining, which is calculated by the HRM method in the case of tunnel lining continuous, the difference is $3.08 \%$. In case of the segmental tunnel lining, the difference value is quite large, is $19.21 \%$ ( $\max$ bending moment in the tunnel segment lining is $88.99 \mathrm{kNm}<110.03 \mathrm{kNm}$ is maximum bending moment in the tunnel lining continuous of Wang's method).

Similarly, compared with the stress value on the tunnel lining. The maximum stress on the tunnel lining continuous of the Wang's method was not significantly different from the maximum stress on the tunnel lining continuous in the Pezien's method (difference of $2.328 \%$ ), with the HRM method, the difference between the maximum stress in the tunnel lining continuous is $2.577 \%$, the difference in the maximum stress of the Wang's method with the $2 \mathrm{D}$ numerical method - used Abaqus program is only $1.546 \%$. However, when comparing the maximum stress value in the tunnel lining continuous of the Wang's method with the maximum stress in the segmental tunnel lining of the HRM method, the difference value is quite large, up to $12.94 \%$. With a comparison of displacement values of the tunnel lining, there is a significant difference for displacements - $d_{\text {max }}$ of the tunnel lining is $42.85 \%$ in two cases: the tunnel lining continuous $\left(\mathrm{d}_{\max }=2.8 \mathrm{~mm}\right)$ and the segmental tunnel lining with segmental joints $\left(\mathrm{d}_{\max }=4 \mathrm{~mm}\right)$, could give conclusions: Under the effect of segmental joints, the segmental tunnel lining is much more flexible, thereby reducing the maximum bending moment in the tunnel lining and reducing the maximum stresses on the tunnel lining under the impact of the earthquake.

\section{CONCLUSIONS}

In this paper, by using different methods to calculate the impact of earthquakes on the tunnel lining, in the case of the tunnel lining continuous and cases of the segmental tunnel lining with segmental joints. Comparison of the results obtained in each method to evaluate the effects of segmental joints in the tunnel lining when the tunnel lining is affected by the earthquake. The paper used the data of a tunnel's cross section of the Hanoi metro system, with the El Centro's earthquake data (that could be as the maximum magnitude earthquake possible in the Hanoi) to use the calculation of the internal force on the tunnel lining in cases the tunnel lining continuous and the segmental tunnel lining with segmental joints. With the results obtained, recognize the positive effects of segmental joints to the operation of the tunnel lining under the impact of the earthquake. These segmental joints increase the flexibility of the tunnel lining under impact of the earthquake. The presence of segmental joints in the tunnel lining reduces the maximum bending moments on the tunnel lining, thus reducing the maximum stress values present on the lining when the tunnel lining is affected by the earthquake.

\section{ACKNOWLEDGMENT}

This study was supported by the Saint Petersburg Mining University, Russia. The authors wish to thank Saint Petersburg Mining University, Russia and Hanoi University Mining and Geology, Vietnam for facilities and resources provided.

The authors would like to express their gratitude to anonymous reviewers for their comments that were very valuable for revising the manuscript. 


\section{REFERENCES}

[1] Anh Do Ngoc. "Numerical analyses of segmental tunnel lining under static and dynamic loads", Ph.D. dissertation. 2014, Lyon, p. 363.

[2] Muir Wood, A. M. "The circular tunnel in elastic ground". Géotechnique, 25(1), 1975, pp.115-127.

[3] Einstein, H. H., \& Schwartz, C. W. "Simplified analysis for tunnel supports". Journal of Geotechnical Engineering, 105, GT4, 1979, pp. 499-517.

[4] Duddeck, H., \& Erdmann, J. "On structural design models for tunnels in soft soil". Underground Space, 9(5-6), pp.246-253.

[5] Oreste, P. P. "A numerical approach to the hyperstatic reaction method for the dimenshioning of tunnel supports". Tunnelling and Underground space technology, 22, 2007, pp. 185-205.

[6] Lee, K. M., \& Ge, X. W. "The equivalence of a jointed shield-driven tunnel lining to a continuous ring structure". Canadian Geotechnical Journal, 38(3), 2001, pp. 461-483.

[7] Blom, C. B. "Design philosophy of concrete linings for tunnel in soft soils". Ph.D. dissertation, Delft University, Netherlands, 2002.

[8] Naggar, H. E., \& Hinchberger, S. D. "An analytical solution for jointed tunnel linings in elastic soil or rock". Canadian Geotechnical Journal, 45, 2008, pp. 1572-1593.

[9] Ding, W. Q., Yue, Z. Q., Tham, L. G., Zhu, H. H., Lee, C. F., \& Hashimoto, T.”Analysis of shield tunnel”. International Journal for Numerical and Analytical Methods in Geomechanics, 28, 2004, pp. 57-91.

[10] Wang, J. N. "Seismic design of tunnels: A state-of-the-art approach", (m. 7. Monograph, Éd.) Brinckerhoff Quade and Douglas Inc., New York, 1993.

[11] Penzien, J., \& Wu, C. L. "Stresses in linings of bored tunnels". Int. J. Earthquake Eng. Struct. Dynamics, 27, 1998, pp. 283-300

[12] Penzien, Z. "Seismically induced racking of tunnel linings". Int. J. Earthquake Eng. Struct. Dynamic, 29, 2000, pp. 683-691.

[13] Do, N. A., Dias, D., Oreste, P. P., \& Djeran-Maigre, I. "A new numerical approach to the Hyperstatic Reaction Method for segmental tunnel linings". International Journal for Numerical and Analytical Methods in Geomechanics, in press, 2014.

[14] Ban quan ly du an duong sat Hanoi., "Thuyet minh du an tau dien ngam Hanoi", Hanoi, 2013, pp.1-55.

[15] Gospodarikov Alexandr and Thanh Nguyen Chi. "Liquefaction possibilityof soil layers during earthquake in Hanoi". International Journal of GEOMATE, 13, 2017, pp. 148-155.

[16] Oreste, P. P." Analysis of structural interaction in tunnels using convergence confinement approach". Tunnelling and Underground space technology, 18, 2003, pp. 347-363.

[17] Do, N. A., Dias, D., Oreste, P. P., \& Djeran-Maigre, I. "2D numerical investigation of segmental tunnel lining behavior". Tunneling and Underground Space Technology, 37, 2013, pp. 115-127.

[18] Mashimo, H., \& Ishimura, T. "Evaluation of the load on a shield tunnel lining in gravel". Tunnelling and Underground Space Technology, 18, 2003, pp. 233-241.

[19] http://www.vibrationdata.com/elcentro.htm.

\section{AUTHOR PROFILE}

Gospodarikov Alexandr is a Professor in the Saint Petersburg Mining University, Russia Federation. His contact E-mail: gospodarikov@mail.ru.

Thanh Nguyen Chi is Postgraduate student in the Saint Petersburg Mining University, Russia Federation. He has been a Master at Hanoi University Mining and Geology, Vietnam. His research geomechanics, material, technology of underground construction. His contact E-mail: nguyenthanh.xdctn47@gmail.com. 